Artículos

\title{
Infodemia y la búsqueda de certezas sobre el COVID-19
}

\section{Infodemia e a busca por certezas sobre COVID-19 \\ Infodemia and the Search for Certainty about COVID-19}

\author{
Vélez Bermello, Gabriela Lourdes; Basilio Franco, Jean Carlo
}

Gabriela Lourdes Vélez Bermello gvelezb@upse.edu.ec

Universidad Estatal Península de Santa Elena, Ecuador

Universidad Nacional de Rosario, Argentina

(iD) Jean Carlo Basilio Franco

jean.basiliofranco@upse.edu.ec

Universidad Estatal Península de Santa Elena, Ecuador

REVCOM. Revista científica de la red de carreras de Comunicación Social

Universidad Nacional de La Plata, Argentina

ISSN: 2451-7836

Periodicidad: Bianual

núm. 12, e058, 2021

redcom.revcom@gmail.com

Recepción: 26 Octubre 2020

Aprobación: 17 Febrero 2021

URL: http://portal.amelica.org/ameli/

jatsRepo/203/2032361010/index.html

DOI: https://doi.org/10.24215/24517836e058

\section{(1) $(9)$}

Esta obra está bajo una Licencia Creative Commons AtribuciónNoComercial-CompartirIgual 4.0 Internacional.
Resumen: En Ecuador, como en otros países, se propagó la pandemia COVID-19 y con ello la desinformación se incrementó. El portal web Ecuador Chequea, categoriza contenidos desde los más apegados a los hechos y los menos creíbles. La labor generada por este sitio pone en duda si realmente actúa en correspondencia a la necesidad de conocer qué tipo de noticias están ligadas a la veracidad de los acontecimientos con relación a la cantidad de noticias falsas y desinformación generadas sobre el virus en el país. La presente investigación aplica una triangulación entre la bibliografía utilizada, un análisis etnográfico digital y una comparación estadística entre la suma de usuarios con el número de la población ecuatoriana que consume Internet. Esta metodología deja como hallazgo destacable que la función de fact-checking podría ser repensada en sus funciones.

Palabras clave: verificación de información, periodismo, comunicación, coronavirus.

Resumo: No Equador, como em outros países, a pandemia COVID-19 se espalhou e com ela aumentou a desinformação. O portal Equador Chequea, categoriza os conteúdos desde os mais vinculados aos fatos e os menos confiáveis; $O$ trabalho gerado por este site questiona se ele realmente atua de acordo com a necessidade de saber que tipo de notícia está ligada à veracidade dos fatos, em relação à quantidade de notícias falsas e desinformações que se geram sobre o vírus no País. Esta pesquisa aplica uma triangulação entre a bibliografia utilizada, uma análise etnográfica digital e uma comparação estatística entre a soma dos usuários com a quantidade da população equatoriana que consome a Internet. Essa metodologia deixa como uma descoberta notável que a função de verificação de fatos poderia ser repensada em suas funções.

Palavras-chave: verificação de informação, jornalismo, comunicação, coronavírus.

Abstract: In Ecuador, as in other countries, the COVID-19 pandemic spread and with it misinformation increased. The web portal Ecuador Chequea, categorizes content from the most attached to the facts and the least credible; The work generated by this site calls into question whether it really acts in accordance with the need to know what type of news is linked to the veracity of events, in relation to the amount of false news and disinformation generated about the virus in the country. 
This research applies a triangulation between the bibliography used, a digital ethnographic analysis and a statistical comparison between the sum of users with the number of the Ecuadorian population that consumes the Internet. This methodology leaves as a remarkable finding that the fact-checking function could be rethought in its functions.

Keywords: verification of information, journalism, communication, coronavirus.

\section{INTRODUCCIÓN}

El inicio del contagio por Coronavirus fue registrado el 1 de diciembre de 2019, teniendo como epicentro la ciudad de Wuhan (China) para luego ser declarado pandemia el 11 de marzo de 2020; con ello se incrementó la búsqueda de información por diferentes medios sobre el virus. Ecuador registró su primer caso el 29 de febrero de 2020.

Con el inicio del Coronavirus la atención de los medios de comunicación fue cada vez más significativa surgiendo, en paralelo, desinformaciones y noticias falsas, las cuales fueron exparricidas en su mayoría en las redes sociales (Salaverría y otros, 2020).

Al principio de la pandemia, la Organización Mundial de la Salud (OMS) advirtió sobre una infodemia, es decir, la rápida propagación de rumores por el ciberespacio. Con la denominación de pandemia al Coronavirus (Covid-19), la presente investigación acoge el nombre de Infodemia, planteado por la OMS, la cual fusiona los términos información y pandemia.

El aumento de noticias falsas se convirtió en una problemática a falta de respuestas de la ciencia ante este virus gripal. $\mathrm{Al}$ ser Internet una herramienta rápida de transmisión de información, muchas personas prestaron atención a contenidos que quizás no contaban con garantías de calidad de información, dejándose llevar por la cantidad de likes compartidos y comentarios, sin considerar la capacidad de daño que ocasiona la desinformación.

En este contexto, se toma en cuenta las categorías de desinformación y fake news bajo el Paradigma EMI que resaltan García-Galera, del Hoyo-Hurtado y Blanco-Alfonso (2020), quienes además explican que "no solo hay una desinformación intencionada que responde a intereses ajenos a los legítimos de un medio de comunicación, sino también una desinformación inconsciente fruto de la pérdida de precisión y de rigor en el desempeño profesional del periodismo, que lo alejaría del servicio al interés público" (García-Galera, del Hoyo-Hurtado \& Blanco-Alfonso, 2020, p. 115).

En Ecuador, fuentes oficiales de comunicación como la Organización Mundial de la Salud (OMS), el Ministerio de Salud, el Comité de Operaciones Emergentes (COE) y la Secretaría de Comunicación del Estado, fueron las encargadas de brindar información directa del caso.

Por su parte, Ecuador Chequea, ${ }^{1}$ el único portal de verificación de los hechos del Ecuador, se dedicó a canalizar contenidos para clasificarlos entre los que se encuentran o no apegados a los hechos. Este medio es parte de los 91 portales certificados por la International Fact-Checking Network (IFCN, 2020).

No obstante, ¿qué tan relevante fue la labor de Ecuador Chequea? ¿Cuántas noticias ha alcanzado a analizar el portal? ¿Es trascendental frente a un público tan diverso? Estas son algunos de las interrogantes que se plantea el estudio.

Aunque muchos medios gubernamentales y no gubernamentales se vieron en la necesidad de emitir consejos para evitar creer en contenidos falsos, como por ejemplo prestar atención a la imagen y el tipo de letra empleado con relación al tipo de letra oficial que utiliza un medio verificado, hay quienes replicaban cadenas de contenido automático, sin siquiera pasar por el filtro del director o un tercero. 
Este trabajo investigativo tiene como propósito analizar la participación del portal Ecuador Chequea frente la infodemia, con el fin de detectar aciertos y desaciertos en esta búsqueda por la veracidad de los hechos.

\section{MARCO REFERENCIAL}

El fact-checking o verificación de hechos es un concepto que ha ganado protagonismo en estas últimas décadas, tanto en el ámbito periodístico, académico e investigativo (Adair \& Thakore, 2015).

Partiendo de sus primeras definiciones y prácticas planteadas por el periodista Brooks Jackson hace más de 20 años (Zommer, 2014), se han sumado muchos aportes para analizarlo desde diferentes aristas. No obstante, todavía es considerado como un concepto esquivo marcado por la presencia de usuarios indiferentes, cómplices en sus burbujas de opinión pública (Cervera, 2017) y de ese poder que ejercen las grandes esferas políticas (Castells, 2009).

Investigadores como Ufarte-Ruiz, Peralta-García y Murcia-Verdú (2018) observan las prácticas de factchecking como un desafío dentro del periodismo.

Zommer (2014) una de las precursoras del fact-checking en América Latina, expone que el método por el cual se realiza una verificación del discurso posee cuatro etapas y ocho pasos. Estas se aplican en el portal web Ecuador Chequea. El primer paso es seleccionar una frase del ámbito público excluyendo contenidos relacionados con la religión, la farándula y los deportes que, generalmente, no son objeto de chequeo.

Para evitar cualquier posible sesgo de la primera etapa, a continuación, se pondera su relevancia. En palabras de Zommer (2017), “este es el paso del método en el que el periodista y su editor tienen un rol protagónico y donde se pone en juego el criterio periodístico"; Visto así, la elección discrecional de las frases podría incidir e interceder en la construcción de las subjetividades.

Entonces, algunas preguntas que podrían surgir serían las siguientes: ¿Cómo se está seguro de que dicha frase es la que el lector necesita conocer (si es verdad o no)? ¿Cómo se garantiza que la selección de la frase es objetiva y no esté ligada a intereses del equipo de chequeo o de la misma organización? En este sentido anclando la palabra objetividad dentro de esta interrogante, y lejos de las posiciones epistemológicas del positivismo y del relativismo o de Jürgen Habermas y Husserl (1995), quienes destacan que el conocimiento es interesado, se podría sostener que es imposible valorar neutralmente.

A su vez, es necesario sostener que la verdad tiene sus diferentes dimensiones; la verdad puede ser una adecuación del discurso a la realidad, enlazado entre la coherencia de lo que se sabe y se piensa e incluso desde la verdad más allá de los hechos, temas que están sustentados bajo el análisis de Verón (Fausto Neto \& Weschendefelder, 2019) y Todorov (1980), entre otros. No obstante, esta categoría está planteada en este trabajo desde un enfoque más crítico tomando como referencia la mirada del filósofo Habermas (1995).

Las siguientes etapas y pasos del fact-checking están ligadas a las consultas de fuentes, a contextualizar y calificar. Este sistema, que sería una especie de rutina productiva periodística, se ve justificado por la cantidad de fake news que han existido y existen actualmente, mucho más potencializados con Internet.

Zommer (2014) creadora del portal argentino Chequeado.com, expone en un capítulo del libro Periodismo Disruptivo la necesidad que tienen los sujetos en conocer si está siendo engañada y, por eso, afirma que el fact-checking va tomando fuerza en distintos países. En este artículo se muestra claramente y en detalle los procesos que conlleva trabajar de chequeador.

\section{Intermediarios y los sitios de chequeo}

Es probable que un primer enfoque esté dado de las funciones que realizan los intermediarios, los cuales se basan en controlar qué es visible o no; dicha actividad se denomina gatekeeper y se aplicaba en medios tradicionales. No obstante, con la irrupción de Internet, las reglas se fueron modificando porque grandes 
empresas webs, por ejemplo, Google y Facebook, controlan lo que se publica. Y así como existen gigantescos conglomerados, están los pequeños mercados, en este caso las páginas de fact-checking.

Esta página de verificación de Ecuador funciona de igual manera como intermediario, por un lado, vigilando y publicando, según sus criterios y paradigmas, qué hechos son consecuentes con la verdad y cuáles no, bajo metodologías que traspasarían la subjetividad; y, por otro lado, sabiendo que, sobre ellos está la estructura web fiscalizando y jerarquizando con algoritmos lo que la sociedad debe mirar más. Estas dos aristas podrían crear ruido en la falta de congruencia hacia la búsqueda inminente por la verdad de los hechos.

Sin embargo, al ser Google un intermediario superior que las plataformas que manejan fact-checking, resultaría una especie de batalla entre David y Goliat, lo que hace de esto un monopolio de información. Por ello Morozov (2013) señala que los acopios de inmensos volúmenes de datos solo podrían ser regulados a través de acuerdos por medio de las Naciones Unidas, en las que no se garantice únicamente la seguridad, sino la exposición adecuada de información.

El control al que se someten las pequeñas plataformas a través de los grandes inspectores, ocasiona la poca visibilidad en la web, por lo que las páginas de fact-checking, no alcanzarían un posicionamiento pertinente en su lucha por esclarecer los hechos.

Con relación a las metodologías, autores como Palau-Sampio (2018) han analizado la metodología de algunos portales similares a Ecuador Chequea, llegando a destacar que existen grandes contrastes al momento de verificar y mostrar los resultados y que es probable que se necesiten mejoras en la construcción de información y los recursos interactivos.

Uscinski \& Butler (2013), por su parte, exponen que las prácticas metodológicas de fact-checking son totalmente objetables, como el hecho de mantener unos pasos que finalmente desembocan en categorizar como predicciones precisas o inexactas manteniendo miradas dicotómicas, análisis que sostuvo el mismo Uscinski (2015) dos años después al caracterizar al fact-checking como una actividad ingenua.

En correspondencia Busaniche (2006) presenta una mirada alternativa de la difusa idea de controlar las opiniones en un mundo de abundante creación de tecnologías, y sostiene la importancia de ver hasta qué punto el fact-checking es la solución a futuro en la búsqueda por la credibilidad de los hechos o, en su defecto, es la muestra exacta del temor en la era de Internet:

Otros fenómenos están en marcha: las comunicaciones interpersonales mediadas por computadoras, la digitalización de la cultura, la distribución de la potestad de crear y generar cultura en cualquier terminal (millones de personas generando, compartiendo contenidos, desarrollando software, incorporándose a las redes no como consumidores, sino como activos participantes, creadores, difusores). Todos estos fenómenos están creando fuertes resistencias en aquellos que ven peligrar sus negocios, o en aquellos que sencillamente le tienen temor a la libertad y a la descentralización casi anárquica que propone la red (Busaniche, 2006, p. 68).

El cuestionamiento a la aplicación de los métodos en las prácticas de chequeo también se ha hecho en Europa con autores como Graves \& Cherubini (2016) quienes indicaron que, pese a que quienes ejercen esta actividad acompañan la idea en común de impulsar la verdad, existen divergencias en cuanto a la identidad y los métodos aplicados. También han existido otras contribuciones de análisis generadas por VázquezHerrero y otros (2019).

Pese a que en Europa existen estos tipos de portales web, Vizoso \& Vázquez-Herrero (2019) sostienen que en América del Sur el auge y el peso de sitios para verificación de hechos son mayores.

Para Rodríguez-Pérez (2020) coexisten dos ámbitos que debe plantearse el fact-checking:

los medios de verificación se encuentran en la encrucijada de erigirse en un poderoso ecosistema que, junto con las alianzas que pueda tejer, sea capaz de luchar contra la desinformación; y, por otro lado, legitimarse socialmente y vencer la desconfianza ciudadana hacia los medios de comunicación” (Rodríguez-Pérez, 2020, p. 245). 
Pese a esto, el fact-checking va tomando fuerza en un mundo cada vez más acelerado, con personas convertidas en prosumidores, viviendo una libertad de expresión que, en ciertos momentos, roza en la impudicia con un ejercicio periodístico estancado.

\section{Las "tétradas" de McLuhan}

Se entiende que, desde el punto de vista epistemológico, lo que define que un discurso pueda ser considerado científico es que tenga dos o tres leyes generales que expliquen los fenómenos generales a esto se le suman los estándares de rigurosidad que luego son validados como conocimiento científico. En este sentido McLuhan encontró cuatro leyes que calan con el proceso que está viviendo el fact-checking, y que pueden ser tranquilamente aplicables al ejemplo de Ecuador Chequea:

Dichas leyes se presentan como "tétradas" a partir de la delimitación de cuatro procesos que ocurren simultáneamente, que son complementarios y que, en conjunto, constituyen un "campo" total de efectos producido por los artefactos: Intensificación; Caducidad; Recuperación; Inversión. Dicho de otro modo, el campo de efectos de un artefacto/medio/ tecnología tiene que ver con estudiar qué intensifica o hace posible el nuevo artefacto; qué hace caducar; qué recupera de formas precedentes; y en qué se convierte llevado al límite de sus funciones (Valdettaro, 2011).

Si bien para McLuhan cualquier cosa es un medio porque todo es mediado, él abre un abanico muy amplio en la comunicación y va haciendo tétradas. Tomando como referencia estas leyes podríamos considerar que la propuesta de Ecuador Chequea se ajusta a esos indicadores:

- Extensión: Cada tecnología extiende una facultad física o psíquica del usuario, lo cual permite desarrollar en el individuo una aptitud. En este caso, Ecuador Chequea presenta una extensión de conocimiento porque otorga una actitud de ilustración al consumidor.

- Caducidad: Cuando un medio se extiende, otro deja de ser utilizado.

$\mathrm{Al}$ ser Ecuador Chequea un medio que brinda una extensión de conocimiento y quizás cierta seguridad en sus seguidores, es probable que vaya ganando espacio y relegando a otros medios aunque en sus objetivos se presenten como un complemento, y no como un reemplazo.

- Recuperación: Todo medio recupera algo previamente obsoleto.

Ecuador Chequea es una recuperación de lo que se supone que en el ejercicio periodístico es una actividad sine qua non. Es decir, verificar la fuente debería ser un paso más dentro de las rutinas productivas.

La llegada de Ecuador Chequea quizás hizo que se volviera a focalizar mejor la verificación de los contenidos La paradoja es que el chequeo, por lo general, se hace luego de que esté publicado y no previamente. De hecho, Silverman (2014) considera que esta función de fact-checking no es más que una actividad determinada y que es parte del marco de verificación tradicional del periodismo.

Con respecto al COVID-19, es probable que portales de chequeo se vieran en la necesidad de incrementar su labor para brindar verificación de los contenidos que constantemente circulan en la web, dejando en evidencia la recuperación de la actividad de verificación de los datos. Ecuador Chequea, publicó información en donde se destacan 192 noticias que dan cuenta de las mentiras sobre el COVID 19 (Ecuador Chequea, 2020).

- Inversión: Cuando una tecnología se lleva al límite, trasciende a sí misma e invierte sus características y pueden emerger características opuestas.

Ecuador Chequea hace la función de verificación de fuentes, pero el hecho de elegir la frase que se sujetará a revisión podría estampar ciertos sesgos, ocasionando que ese grado de credibilidad que desea ganar en la verificación se invierta y los usuarios lleguen a preguntarse por qué chequear esa frase o aquella Esto 
podría ocasionar lo opuesto a lo que estas organizaciones pretenden Y surgiría, entonces, la desconfianza. La pregunta que se podría formular sería, entonces, la siguiente: ¿quién chequea a Ecuador Chequea?

\section{Metodología}

Este trabajo investigativo se basa en un método inductivo, teniendo como caso de estudio Ecuador Chequea, único portal web de chequeo en el país.

Como primera fase de la investigación se analizaron y contrastaron conceptos bibliográficos enmarcados en la verdad y la construcción de la realidad. La herramienta informática Atlas.ti se usó para la codificación de los textos y el desarrollo de los contenidos.

La segunda fase se desarrolló entre el 29 de febrero (fecha en la cual se detectó el primer caso de COVID-19 en Ecuador) y el 29 de septiembre del 2020 a partir de una investigación de etnografía digital. En esta etapa se analizaron los contenidos que Ecuador Chequea difundió a través del sitio web y en la Fan Page en Facebook, Twitter, Instagram y YouTube sobre COVID-19 en Ecuador. Se usó como herramienta una tabla dinámica de Excel, con el fin de mantener la actualización de los datos.

Si bien Ecuador Chequea tiene una conexión más cercana con la audiencia a través de WhatsApp, esta aplicación fue excluida de la investigación porque el sistema de información se vuelve más privado y poco accesible a los datos.

Para esta primera etapa se utilizó la categorización que Ecuador Chequea da a las noticias luego de analizarlas a partir de las siguientes denominaciones; "Cierto", "Sí, pero", "Insostenible" "Falso" y "A Profundidad". Estas cinco categorías y sus conceptos están especificadas en el apartado de Investigación etnográfica digital donde se estacan los hallazgos.

Finalmente, se realizó una comparación estadística entre el número de seguidores por cada plataforma en la que Ecuador Chequea tiene una cuenta, con el número de la población ecuatoriana que consume Internet, de acuerdo al Instituto Nacional de Estadística y Censo (2019).

Esta triangulación permite desembocar en un análisis de cómo está funcionando el portal frente a las noticias falsas y la desinformación. En síntesis, la triangulación de métodos de recolección de datos se basa en:

- Análisis bibliográfico.

- Investigación etnográfica digital.

- Relevamiento y análisis de los usuarios que siguen a Ecuador Chequea en las distintas plataformas.

Este planteamiento metodológico de triangulación de métodos de recolección, se enmarca en los parámetros establecidos por Sampieri, Fernández \& Baptista (2014) según los cuales "en la indagación cualitativa poseemos una mayor riqueza, amplitud y profundidad de datos si provienen de diferentes actores del proceso, de distintas fuentes y de una mayor variedad de formas de recolección" (Sampieri, Fernández \& Baptista, 2014, p. 417).

De esta forma se sistematizan los datos y se consigue una interacción entre la recolección y el análisis que desemboca en las conclusiones finales.

\section{HALLAZGOS}

\section{Análisis bibliográfico}

Dentro de la contrastación bibliográfica se puede evidenciar la confrontación entre investigadores que opinan que las páginas de chequeo, y en este caso la de Ecuador Chequea, serían, por un lado, un aporte a la sociedad 
(Zommer, 2014; Becerra, 2016) y por otro, que cumple con una especie de espejismo que tiene el fin de brindar cierta seguridad de los hechos (Uscinski \& Butler, 2013; Uscinski, 2015; Busaniche, 2006.)

\section{Investigación etnográfica digital}

En esta fase se analizaron los contenidos difundidos a través del portal web Ecuador Chequea, la fan page en Facebook, Twitter, Instagram y YouTube, considerando la información analizada sobre temas específicos de COVID-19 en Ecuador hasta el 29 de septiembre de 2020.

El total de registros que el portal web Ecuador Chequea tiene hasta esa fecha es de 192 noticias verificadas en torno al Covid-19, de las cuales 67 noticias son específicamente de Ecuador. Estas últimas fueron objeto de este estudio.

Los parámetros, categorías y elementos para alcanzar los siguientes resultados están sujetos a la metodología de valoración de las noticias del portal Ecuador Chequea, las cuales son:

Cierto: Las declaraciones de los sujetos políticos que son integralmente precisas, directamente congruentes con la fuente objetiva, y no omiten datos ni limitan la contextualización de la temática en discusión.

Dentro de nuestra iconografía, hemos sintetizado esta categoría con la figura de una batería completamente cargada.

Sí, pero: Los enunciados que incluyen información verificable o datos parcialmente veraces, por lo cual requieren mayores ejercicios de contextualización para determinar, con claridad y precisión, el nivel de acierto de la afirmación de un actor político.

Insostenible: Toda expresión que no permite identificar directamente los argumentos o las bases de datos de las cuales se haya desprendido dicho enunciado. En esta categoría no se adelanta criterio sobre la certeza o falsedad de una declaración hasta ubicar con precisión la fuente objetiva con la cual confrontar aquella información.

Una batería a medio descargar es el símbolo en este nivel. Evocación de los apuros que pueden afrontar los sujetos políticos que hablan sin sustento.

Falso: Una declaración que entra en tensión abiertamente con el dato objetivo, un argumento falaz. Sin más, una mentira comprobada...

El uso de información falsa termina por agotar la batería. Por eso la ciudadanía deberá estar «pilas» con la verdad (Ecuador Chequea, 2020).

A esta categoría se incluyen la denominación "Falseta".

A profundidad: Una categoría nueva que se incorporó con el inicio de la pandemia.

Bajo estos parámetros surgen los siguientes resultados:

TABLA 1

Categorías, número de noticias chequeadas y porcentaje.

\begin{tabular}{|l|l|l|}
\hline $\begin{array}{l}\text { Nivel de } \\
\text { Comprobación } \\
\text { (Categorias) }\end{array}$ & $\begin{array}{l}\text { Número de noticias } \\
\text { chequeadas en } \\
\text { Ecuador }\end{array}$ & Porcentaje \\
\hline Cierto & 15 & $22 \%$ \\
\hline Sí, pero & 9 & $14 \%$ \\
\hline Insostenible & 12 & $18 \%$ \\
\hline Falso & 16 & $24 \%$ \\
\hline A profundidad & 15 & $22 \%$ \\
\hline TOTAL: & 67 & $100 \%$ \\
\hline
\end{tabular}

Fuente: elaboración propia 


\section{Análisis de los usuarios que siguen a Ecuador Chequea en las distintas plataformas}

Según el Instituto Nacional de Estadística y Censo (2019), Ecuador tiene 17.46 millones de habitantes, de estos un total de 13,8 millones de personas (79\%) cuentan con acceso a internet. Esta estadística es elevada en comparación con los seguidores que tiene Ecuador Chequea en las siguientes redes sociales (fecha de corte hasta el 29 de septiembre de 2020):

\section{Facebook}

Me Gusta: 14,301

Seguidores: 15,011

Instagram

Seguidores: 1,105

YouTube

Suscriptores: 1,180

Twitter

Seguidores: 12,120

\section{Discusión}

El fact-checking, como mecanismo de detección de noticias falsas y errores en los medios de comunicación, aún posee ambigüedades, que han sido resaltadas por Uscinski \& Butler (2013), Uscinski (2015), entre otros, y quienes, a su vez, mantienen una oposición radical. Se ha llegado al punto de cuestionar las funciones de verificación que no se estaban cumpliendo dentro de las redacciones, es decir, en las rutinas productivas.

Por otro lado, la labor de quienes hacen chequeo es compleja y ardua, desde el punto de vista de la responsabilidad por tratar de aproximarse a la veracidad de los hechos, contando en sus salas con especialistas en estadísticas, periodistas e informáticos. Zommer (2014) defiende la idea de que este proceso es un aporte a la sociedad frente a la avalancha de información falsa o contenido dudoso.

Ahora bien, desde un punto de vista particular, esta investigación sopesa la idea de que el periodismo debe recobrar el chequeo de información previo a las publicaciones y tiene que desligar su mirada a la competitividad e inmediatez, para lo cual es necesario que recupere las bases epistemológicas de la profesión y que sea ella misma quien acoja mecanismos tecnológicos con los que construya mejores informaciones.

Si bien la mayor parte de portales de chequeo hacen este proceso luego de que los medios publican algo, escasos medios de comunicación tienen dentro de sus redacciones a un personal encargado de la verificación de fuentes. La ciudadanía está ávida de contenidos y es allí donde el periodismo debe apropiarse de lo que, por naturaleza, es suyo: la verificación de los hechos tomando en cuenta los preceptos de la profesión.

\section{Conclusiones}

Después de analizar y contrastar diversas teorías, sistematizar los datos a partir de la etnografía digital y verificar el número de personas que en Ecuador consumen internet, se podría indicar que en un mundo mediatizado es importante que las funciones del fact-checking se vean apoyadas por procesos más profundos de Inteligencia Artificial, en la que desde sus algoritmos sea mínimo el margen de error para corroborar hechos.

Por el escaso número de noticias verificadas en torno al COVID-19 en Ecuador, es posible inferir, quizás, que la falta de información en diversos medios en general, sobre la solución final contra el virus y el hecho de 
no encontrar certezas, desembocaría en que el usuario dedique tiempo en buscar fuentes alternativas con el fin de sentirse informado, aunque en la práctica no sea así.

El contenido científico no cambia porque los parámetros generales no varían, las noticias científicas que ya salieron por fuentes oficiales dejan de ser consumidas por lo que el usuario desea otra información y por ello acuden a contenidos alternativos, llevando incluso a generar chistes, memes, comentarios, etc.

Ante esto, la OMS habla de una doble pandemia: por un lado, la de la desinformación y, por otro, del coronavirus en temas de salud. El resultado de ello es que minuto a minuto comienza el intercambio de contenidos entre pares y la información científica se ve opacada.

Desde este punto de vista, las acciones de portales de chequeo podrían dar cabida a un verdadero posicionamiento del fact-checking en su imperiosa búsqueda por aclarar sucesos; según los hallazgos se podría inferir que detrás de este proceso no deberían estar solo periodistas, sino profesionales especializados en análisis de sistemas e incluso un mayor apoyo de programas de Inteligencia Artificial, con los cuales se logren reducir los sesgos metodológicos que se aplican al momento de analizar un tipo de contenido.

Sin embargo, la tecnología, de la mano de Internet, no será, precisamente, la salvación, sino un acompañamiento al trabajo comunicacional y para llegar a ese equilibro se abrirán grandes debates. En efecto como indica Lessig (1998) el mundo del ciberespacio, tiene su arquitectura, sus restricciones y donde la libertad no está asegurada, pero tampoco se alinea hacia la construcción de una realidad coherente.

La verificación de información y en particular, la labor del portal web Ecuador Chequea, cala en el análisis de las leyes de McLuhan, tomando en cuenta el enfoque epistemológico.

Las leyes brindadas por el filósofo canadiense se sostienen aún en esta época de convergencia mediática: "Los fenómenos actuales de la mediatización demuestran, sin dudas, la absoluta vigencia de la "ecología de los medios" mcluhaniana (Valdettaro, 2011).

Es posible que el ciudadano tenga que otorgarle de nuevo su fe a las rutinas productivas, que se refieren a todo el proceso que conlleva la construcción de una noticia, en el que se establecen dos campos de estudio y análisis de la misma, se trata de gatekeeping -cuidado de la puerta o del acceso-y posteriormente newsmaking -construcción de la noticia-.

Considerando el tema de estudio al fact-checking en función a los denominados intermediarios, se podría expresar que este está inmerso en una paradoja, es decir, en una contradicción desde el punto de vista lógico, porque aquellas plataformas webs que están monopolizando todo no permiten el fluido de la construcción de la realidad, el cual debe ajustarse a hechos corroborados como lo que pretende hacer el fact-checking.

Si se comienza a profundizar en la pregunta que el filósofo Watzlawick (2011) postula (¿hasta qué punto es real lo que ingenuamente y sin el menor reparo solemos llamar realidad?), se llegaría a un debate histórico. Lo que sí queda claro es en que al final "todos pertenecemos" a Google y ponerse en contra podría ocasionar problemas, como los que vivió Alemania (Mechanism, 2014), porque por el momento, los grandes intermediarios son Facebook y Google (Fontevecchia, 2018) dominadores del poder o monarquía comunicacional como sentencia Castells (2009), aunque otros autores como Elola (2018) diga que existe la necesidad de rebelarse contra estos manipuladores.

La rebeldía tal vez no sea la salida, sino que es fundamental que los organismos pertinentes homologuen sus ideas de control en el ciberespacio (Véliz, 2018). Abriendo más el espectro, la web y los potenciales intermediarios están manteniendo a los pequeños mercados webs en una Espiral del Silencio (NoelleNeumann,1995), donde el mutismo se imprime bajo algoritmos que adiestran el ritmo de la información circulante y a quienes están dentro del juego sólo les toca callar y aceptar las reglas. Y, como añadido a la situación, las redacciones de los medios están sumidas en una convergencia (Becerra, 2016) que acelera el ritmo de producción y no la calidad.

Lo manifestado mantiene a los suscritores, usuarios y/o seguidores, ensimismados en una realidad. Platón lo detalla, por ejemplo, en el mito de la caverna, aquella metáfora filosófica que explica cómo vive la sociedad, atrapada en la ficción, envuelta en una realidad. 
Vislumbrando el devenir del incremento de información en Internet, no solo alrededor del virus sino de muchos temas, es probable que con el pasar del tiempo la sociedad sea arrastrada hacia un miedo social, en el que la privacidad sería solo una palabra en el olvido del diccionario cualquiera que fuera su idioma porque, así como Bauman (2015) manifiesta que atravesamos tiempos de modernidad líquida pronto esa modernidad pasará a ser gaseosa, una vida social más difusa donde el ser humano sienta terror porque así como el consume experiencias, relaciones, cuestiones materiales, en algún momento será consumido y desechado.

\section{REFERENCIAS}

Adair, B. and Thakore, I. (2014). Fact-Checking Census finds continued growth around the world. Reporterslab. Recuperado de https://reporterslab.org/fact-checking-census-finds-growth-around-world

Bauman, Z. (2015). Catedraepistemologia. Recuperado de https://catedraepistemologia.files.wordpress.com/2009/0 5/modernidad-liquida.pdf

Becerra, M. (17 de mayo de 2016). La convergencia es más que un proyecto de ley. Quipu. Recuperado de https://ma rtinbecerra.wordpress.com/2016/05/17/la-convergencia-es-mas-que-un-proyecto-de-ley/

Busaniche, B. (2006) Prohibido pensar, propiedad privada: los monopolios sobre la vida, el conocimiento y la cultura. Córdoba, Argentina: Fundación Vía Libre

Castells, M. (2009). Comunicación y poder. Madrid, España: Alianza.

Cervera, J. (28 de noviembre de 2017). El futuro del periodismo es ciborg. Cuadernosdeperiodistas. Recuperado de ht tp://www.cuadernosdeperiodistas.com/futuro-del-periodismo-ciborg/

Ecuador Chequea (2020). Las mentiras sobre el COVID 19 en Ecuador. Recuperado de http://www.ecuadorcheque a.com/las-mentiras-sobre-el-covid-19-en-ecuador

Elola, J. (16 de febrero de 2018). Rebelión contra las redes sociales. El Pais. Recuperado de https://elpais.com/tecno logia/2018/02/16/actualidad/1518803440_033920.html

Fausto Neto, A. y Weschenfelder, A. (2019). Eliseo Verón. Mediatización de la política: trayectorias. InMediaciones de la Comunicación, 14(2), 235-257. Recuperado de https://revistas.ort.edu.uy/inmediaciones-de-la-comunica cion/article/view/2928

Fontevecchia, J. (25 de marzo de 2018). Facebook y Google. Perfil. Recuperado de https://www.perfil.com/noticias /columnistas/facebook-y-google.phtml

García-Galera, M. d. C., del Hoyo-Hurtado, M. y Blanco-Alfonso, I. (2020). Desinformación e intención comunicativa: una propuesta de clasificación de fake news producidas en entornos periodísticos profesionales. Revista Mediterránea de Comunicación, 11(2), 105-118. https://www.doi.org/10.14198/MEDCOM2020.11. 2.16

Graves, L. y Cherubini, F. (2016). El auge de los sitios de verificación de hechos en Europa (Informe de noticias digitales del Instituto Reuters). Oxford, United Kingdom: Instituto Reuters para el Estudio del Periodismo.

Habermas, J. y Husserl, E. (1995). Conocimiento e interés/La filosofía en la crisis de la humanidad europea. Valencia, España: Universitat de València.

IFCN Code of Principles [Código de principios de la IFCN]. (2020). Retrieved from https://ifcncodeofprinciples. poynter.org/signatories

Lessig, L. (1998). Las leyes del ciberespacio. THËMIS-Revista de Derecho, (44), 171-179.

Mechanism, M. A. (2014). Children and Armed Conflict [Niños y conflict armado]. Recuperado de https://childrena ndarmedconflict.un.org/wp-content/uploads/2016/04/MRM_Field_5_June_2014.pdf

Morozov, E. (29 de septiembre de 2013). Regular la batalla por la información. El País. Recuperado de https://elpai s.com/elpais/2013/09/10/opinion/1378809537_719906.html

Noelle-Neumann, E. (1995). La espiral del silencio. Barcelona, España: Paidós. 
Palau-Sampio, D. (2018). Fact-checking y vigilancia del poder: La verificación del discurso público en los nuevos medios de América Latina. Communication \& Society, 31(3), 347-363. Recuperado de https://hdl.handle.net/ $10171 / 55807$

Rodríguez-Pérez, C. (2020). Una reflexión sobre la epistemología del fact-checking journalism: retos y dilemas. Revista de Comunicación, 19(1), 243-258. https://doi.org/10.26441/RC19.1-2020-A14

Salaverría, R., Buslón, N., López-Pan, F., León, B., López-Goñi, I. y Erviti, M. (2020). Desinformación en tiempos de pandemia: Tipología de los bulos sobre la covid-19. El Profesional de la Información, 29(3). https://doi.org/10 .3145/epi.2020.may.15

Sampieri, R., Fernández, C. y Baptista, P. (2014). Metodología de la investigación. Ciudad de México, México: Editores, SA de CV.

Silverman, C. (2014). Verification handbook. Additional materials to verifying digital content for emergency coverage [Manual de verificación. Materiales adicionales para verificar contenido digital para cobertura de emergencia]. Países bajos: European Journalism Center.

Todorov, T. (1980). Introducción a la literatura fantástica. Ciudad de México, México: Premia editora. http://ieslite ratura.ftp.catedu.es/lectura/cuarto_atras/imagenes/Todorov.pdf

Ufarte-Ruiz, M., Peralta-García, L. y Murcia-Verdú, F. (2018). Fact checking: Un nuevo desafío del periodismo. El Profesional de la Información, 27(4), 733-741. https://doi.org/10.3145/epi.2018.jul.02

Uscinski, J. E. y Butler, R. W. (2013). The epistemology of fact checking [La epistemología de la verificación de hechos]. Critical Review, 25(2), 162-180.

Uscinski, J. E. (2015). La epistemología de la verificación de hechos (todavía es ingenua): Dúplica a Amazeen. Revisión critica, 27(2), 243-252.

Valdettaro, S. (Coord.). (2011). El dispositivo McLuhan. Recuperaciones y derivaciones. Rosario, Argentina: UNR Editora

Vázquez-Herrero, J., Vizoso, Á. y López-García, X. (2019). Innovación tecnológica y comunicativa para combatir la desinformación: 135 experiencias para un cambio de rumbo. El profesional de la información, 28(3). https://do i.org/10.3145/epi.2019.may.01

Véliz, C. (4 de abril de 2018). Por qué es importante proteger nuestra privacidad en internet. New York Times. Recuperado de https://www.nytimes.com/es/2018/04/04/espanol/opinion/opinion-veliz-facebook-privadida d-cambridge-analytica.html

Vizoso, Á. y Vázquez-Herrero, J. (2019). Plataformas de fact-checking en español. características, organización y método. Comunicación y Sociedad, 32(1), 127-144. https://doi.org/10.15581/003.32.1.127-144

Watzlawick, P. (2011). ¿Es real la realidad? Confusión, desinformación, comunicación. Barcelona, España: Herder.

Zommer, L. (2014). El boom del fact-checking en América Latina. Aprendizajes y desafíos del caso de Chequeado.

Zommer, L. (2017). Fact-checking y periodismo de datos. Recuperado de https://journalismcourses.org/es/news/ce ntro-knight-ofrece-nuevo-curso-gratuito-en-espanol-fact-checking-y-periodismo-de-datos-inscribete/

\section{Notas}

1 Es el primer medio dedicado a la verificación del discurso público y los contenidos engañosos que circulan en Internet. La plataforma es una iniciativa de Fundamedios. Ecuador Chequea detalla que es organización sin fines de lucro (http ://www.ecuadorchequea.com). 